\title{
Histogenetic Study of Verruciform Xanthoma of the Gingiva
}

Hiromitsu Yamamoto ${ }^{1}$ and Mariko Kawai ${ }^{1,2^{*}}$

${ }^{1}$ Department of Oral and Maxillofacial Surgery, Graduate School of Medicine, Kyoto University, Kyoto, Japan

${ }^{2}$ Department of Pharmacology, Osaka Dental University, Osaka, Japan

*Corresponding author: Kawai M, Department of Pharmacology, Osaka Dental University, Osaka, Japan, Tel: 81-80-3132-3762; E-mail: kawai-m@cc.osaka-dent.ac.jp

Received date: June 01, 2018; Accepted date: June 12, 2018; Published date: June 19, 2018

Copyright: (c) 2018 Yamamoto $\mathrm{H}$, et al. This is an open-access article distributed under the terms of the Creative Commons Attribution License, which permits unrestricted use, distribution, and reproduction in any medium, provided the original author and source are credited.

\begin{abstract}
Verruciform xanthoma is characterized macroscopically by papillomatous or verrucous hyperplasia of the mucosal epithelium and histopathologically by papillary epithelial hyperplasia and foam cell accumulation in the lamina propria between epithelial processes. This relatively rare lesion does not appear to be a true tumor, but rather an inflammatory event. Here, verruciform xanthoma of the gingiva was subjected to histopathological and immunohistochemical analyses. Notably, the cortical layer of the lesion exhibited a verrucous and granular outer surface, similar to a papilloma. Within the lesion, keratinized stratified squamous epithelium and epithelial process extensions were observed, and the connective tissue between clubbed epithelial processes was filled with foam cells. These foam cells exhibited strong cytoplasmic and membrane expression of CD68, a1-antitrypsin, and macrophage scavenger receptor-1 (MSR-1), as well as human leukocyte antigen (HLA)-DR and oxidized low-density lipoprotein cholesterol (ox-LDL). The epithelial cells also expressed HLA-DR in the cytoplasm and cell membrane. By contrast, the expression of S-100 and CD1a in Langerhans cells was clearly reduced in the epithelium of the verruciform xanthoma, while the inflammatory infiltrating cell population comprised of mainly CD3- or CD8-positive cells, with few CD20- or CD4-positive cells. The increased lipid content of the cell membrane and concomitant epithelial hyperplasia causes cellular injury and leakage into the connective tissue consistent with dysregulated cellular immunity in the stratified squamous epithelium. Accordingly, it may be concluded that macrophages phagocytose these lipids and differentiate to foam cells.
\end{abstract}

Keywords: Verrucifor xanthoma; Foam cells; CD68; Epithelial hyperplasia; Inflammatory cell infiltration

\section{Introduction}

Xanthomas are dermal lesions attributed to lipid or lipoprotein disorders. Within this category, lesions of the oral region that exhibit papillomatous hyperplasia are classified as verruciform xanthoma [1]. These relatively rare lesions are characterized histologically by epithelial papillary hyperplasia and foam cell accumulation in the lamina propria between epithelial processes [2-8].

Two theories have been proposed to describe the histogenetic mechanism underlying verruciform xanthoma. In the first, epithelial papillary hyperplasia is triggered by an inflammatory response (e.g., chronic stimulation), and underlying macrophages subsequently phagocytose lipids from the cell membranes of the modified epithelial cells and differentiate to foam cells [2,9]. In the second hypothesis, a lipid metabolic abnormality occurs consequent to delayed inflammation or repetitive mechanical stimulation, after which macrophages in the connective tissue differentiate to foam cells; in this scenario, papillary hyperplasia of epithelium is a secondary event [10]. To date, neither hypothesis has been confirmed.

In addition to the mechanistic uncertainties, few reports have addressed the epithelium and inflammatory cells associated with verruciform xanthoma, although an understanding of these factors is needed to elucidate the guidelines for and characteristics of this disease. Therefore, this report describes a histogenetic study of verruciform xanthoma of the gingiva based on histopathological and immunohistochemical analyses.

\section{Materials and Methods}

\section{Clinical information}

A 29-year-old man presented to our dental office in December 2015 for an evaluation of a painless swelling on the labial side of the marginal gingiva around the lower right medial incisor. He had long noticed the small lesion but had not previously sought consultation at a medical institution and was referred to our clinic by his regular dentist. The lesion measured $5 \mathrm{~mm} \times 2 \mathrm{~mm}$ and matched the color of the gingiva. Additionally, it was sharply marginated, with a granular surface and soft elasticity at the affected gingiva. Although the associated incisor had a normal tooth crown, the surrounding gingiva exhibited slight redness and swelling. X-ray findings showed no abnormality. The tumor was resected en bloc under local anesthesia.

\section{Histological analysis}

The specimens were fixed in $10 \%$ neutral buffered formalin, embedded in paraffin, and cut into 7 -mm-thick sections. The sections were stained with hematoxylin and eosin according to a routine procedure and observed with a light microscope (CX41; Olympus Corp., Tokyo, Japan).

\section{Immunohistochemical analysis}

For the immunohistochemical analysis, the specimens were fixed, embedded, and cut as described above, and labeled using an indirect peroxidase-labeled streptavidin-biotin technique (DAKO, Glostrup, Denmark). The antibodies used for immunohistochemistry, Negative controls were incubated with phosphate-buffered saline (PBS) instead 
of antibodies, Normal tissue adjacent to the lesion (i.e., without inflammation) was used as the control tissue.

\section{Results}

\section{Histological analysis}

In hematoxylin and eosin-stained sections of the verruciform xanthoma, the outer side of the cortical layer exhibited a verrucous and granular appearance similar to a papilloma. Stratified squamous epithelium with keratinization and extended epithelial processes were also observed. The connective tissue between the clubbed epithelial processes was filled with foam cells, and the extended connective tissue exhibited densely aggregated foam cells and an increase in the number of enlarged capillary vessels. Furthermore, lymphocytic inflammatory cell infiltration occasionally with the focal region was also observed there (Table 1 and Figures 1-3).

\begin{tabular}{|l|l|l|}
\hline Antibodies & Clone & Source \\
\hline CD68 & PGM-1 & Dako/Agilent Technologies \\
\hline HLA-DR & Polyclonal & Dako/Agilent Technologies \\
\hline ox-LDL & TAL-1B5 & Dako/Agilent Technologies \\
\hline S-100 & Polyclonal & Bioss Antibodies \\
\hline CD1a & Polyclonal & Roche Diagnostics \\
\hline CD3 & EP3622 & Cell Marque/Sigma-Aldrich \\
\hline CD20 & 2 GV6 & Roche Diagnostics \\
\hline CD8 & L26 & Roche Diagnostics \\
\hline CD4 & C8/144B & Nichirei Biosciences \\
\hline
\end{tabular}

Table 1: Immunohistochemical analysis.

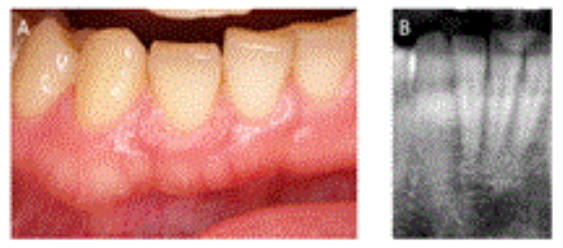

Figure 1: Clinical findings, A: The tumor was $5 \times 2 \mathrm{~mm}$, gingival color, sharply marginated, granular surface, and soft elasticity at the affected gingiva of lower right medial incisor. Although the tooth crown of the incisor was normal, the surrounding gingiva exhibited slight redness and swelling. B: X-ray findings. No abnormality was shown.

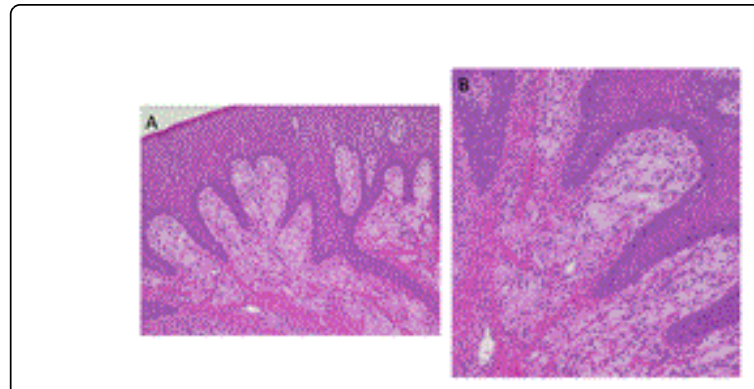

Figure 2: Histological analysis, the sections were stained with hematoxylin and eosin. Stratified squamous epithelium with keratinization and extended epithelial processes were observed. Connective tissue between epithelial processes was filled densely aggregated foam cells. Lymphocytic Inflammatory cell infiltration was also observed in extended connective tissue. A; $\times 40, \mathrm{~B} ; \times 100$.

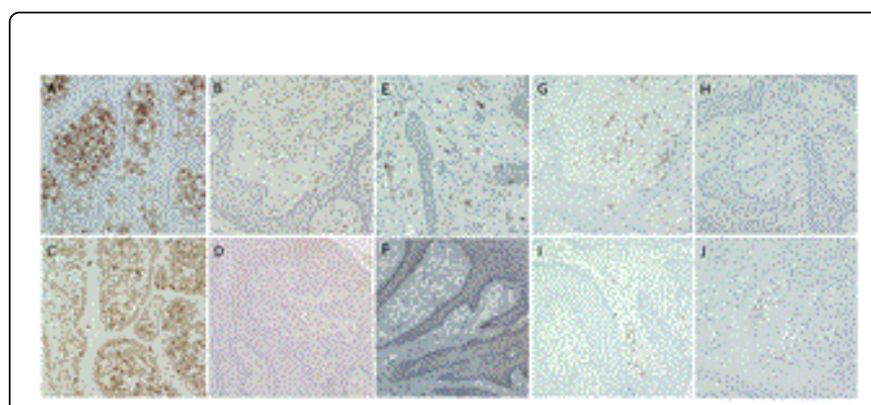

Figure 3: Immunohistochemical analyses, the foam cells exhibited strong cytoplasmic and cell membrane expression of CD68 (A), a1antitrypsin (B). HLA-DR (C), and ox-LDL (D) were also detected on foam cells. A-D; $\times 200$. A clear reduction in the population of S-100 protein- (E) and CD1a- (F) positive cells was observed. E, F; $\times 200$. The inflammatory infiltrating cells mainly comprised CD3(G) or CD8- (H) positive cells, with few CD20- (I) or CD4- (J) positive cells. G-J; $\times 200$.

\section{Immunohistochemical analysis}

The foam cells exhibited strong cytoplasmic and cell membrane expression of CD68, a1-antitrypsin, and macrophage scavenger receptor-1 (MSR-1). Human leukocyte antigen (HLA)-DR and oxidized low-density lipoprotein (ox-LDL) were also detected on foam cells (Figure 3A-3D, and data not shown). The epithelial cells also expressed HLA-DR and ox-LDL in the cytoplasm and cell membrane. However, a clear reduction in the population of S-100 protein- and CD1a- positive Langerhans cells was observed (Figure 3E and 3F). The inflammatory infiltrating cells mainly comprised CD3- or CD8positive cells, with few CD20- or CD4-positive cells (Figure 3G-3J). An abundance of infiltrating cells was observed in the epithelium of the verruciform xanthoma epithelium compared to that of normal tissue.

\section{Discussion and Conclusion}

Verruciform xanthoma, a relatively rare condition, most frequently affects the oral mucosa and genital skin. As noted above epithelial 
papillary hyperplasia and foam cell accumulation between epithelial processes are characteristic of this type of lesion [1]. Many cases of verruciform xanthoma are clinically diagnosed as papilloma, as they appear on the surface of the oral mucosa as papillary or verrucous tumors with a gingival or yellowish-white color [2-8]. The mucogingival mucosa is relatively frequently affected, and most lesions in this area are smaller than $15 \mathrm{~mm}$ in diameter [4,11,12]. These lesions commonly affect middle-aged and older people, which suggests that existing gingivitis and periodontitis may be involved in the occurrence of a verruciform xanthoma in the oral region $[3,5]$.

As the lesion in the current case had a granular surface, clear boundary, localized proliferation, and a diameter consistent with previous reports, a clinical diagnosis of gingival papilloma was considered. However, the relatively young age of the patient meant that long-term chronic mechanical stimulation was unlikely. Histopathology of the resected lesion revealed an outer layer of stratified squamous epithelium, papillomatous hyperplasia with prolonged, clubbed, deeply epithelial processes, and accumulations of foam cells and extended capillary vessels in the connective tissue between epithelial processes. Additionally, the connective tissue was highly infiltrated with superficial localized lymphocytes and neutrophils [1-5]. These typical histopathological findings facilitated a diagnosis of verruciform xanthoma.

Various local epithelial proliferative diseases, including lichen planus, leukoplakia, pemphigus vulgaris, and carcinoma in situ, have been reported to occur concomitantly with oral verruciform xanthoma, and skin verruciform xanthomas have also reported as concomitant symptoms of many epithelial proliferative diseases. Therefore, some researchers insist that verruciform xanthoma is a secondary disease [13].

In addition to histological features, verruciform xanthoma can also be identified using immunohistochemical characteristics. For example, the foam cells detected in the connective tissue appear to originate from migrating/inflammatory macrophages and can be detected immunohistochemically using antibodies specific for CD68 and a1antitrypsin [2-8]. Additionally, the detection of HLA-DR suggests Tlymphocyte-mediated immunological activation, which may aggravate inflammation [14]. In both previous reports and the present case, the inflammatory infiltrating cells were believed to comprise mainly $\mathrm{T}$ lymphocytes, [15] particularly CD8-positive T-lymphocytes, which are dominant and may contribute to the development of verruciform xanthoma.

In contrast to the above-described markers, the foam cells in this case did not express S-100 protein or CD1a, which are markers of epithelial tissue-resident macrophages or Langerhans cells, which act as antigen presenting cells in the mucosa. This result corresponds to previous reports, wherein many positive cells were detected in the normal epithelial layers [7,16-18]. The reason for this result is not clear, although some researchers reported a counter-regulatory mechanism involving a decrease of Langerhans cells and increase in subepithelial macrophages [19].

In the present study, ox-LDL was strongly expressed in the epithelium of the verruciform xanthoma. In inflammatory diseases, epithelial hyperplasia of the stratified squamous epithelium is often associated with an increase in membrane lipid levels [20,21]. Using electron microscopy, Suka [15] reported the loss of basement membrane, degeneration of the basal cells, and disruption of the intracellular junction, which led to the leakage of lipids from the broken epithelium [20]. In turn, these lipids were oxidized by macrophages, and the resulting ox-LDL is incorporated into the cells via MSR-1. Finally, the macrophages become foam cells [22,23]. The foam cells in this case expressed both ox-LDL and MSR-1, indicating that MSR-1-positive macrophages accumulated in the papillary area of the connective tissue, where they phagocytosed lipids released from epithelial or basal membranes and transitioned to foam cells within the verruciform xanthoma.

As noted in the introduction, there are two theories regarding the histogenetic of verruciform xanthoma. As the present case was unlikely to have involved long-term mechanical stimulation, it is more likely to follow the process of the first theory due to an inflammatory reaction such as periodontitis. It is appropriate to be concluded that increasing the lipid content while epithelial hyperplasia leaks into the connective tissue caused by cellular injury, consistent with dysregulated cellular immunity in the stratified squamous epithelium, and the phagocytosis of these lipids by macrophages was occurred, which then differentiate into foam cells.

\section{Consent}

Written informed consent was obtained from the patient for publication of this report and any accompanying figure.

\section{References}

1. Shafer WG (1971) Verruciform xantoma. Oral Surg Oral Med Oral Pathol 31: 784-789.

2. Hedge U, Doddawad VG, Sreeshyla HS, Patil R (2013) Verruciform xanthoma: A view on the concepts of its etiopathogenesis. J Oral Maxillofac Pathol 17: 392-396.

3. de Andrade BA, Agostini M, Pires FR, Rumayor A, Carlos R, et al. (2015) Oral verruciform xanthoma: A clinicopathologic and immunohistochemical study of 20 cases. J Cutan Pathol 42: 489-495.

4. Oliveira PT, Jaeger RG, Cabral LA, Carvalho YR, Costa AL, (2001) Verruciform xanthoma of the oral mucosa- Report of four cases and a review of the literature. Oral Oncol 37: 326-331.

5. Philipsen HP, Reichart PA, Takata T, Ogawa I (2003) Verruciform xanthoma-biological profile of 282 oral lesions based on a literature survey with nine new cases from Japan. Oral Oncol 39: 325-336.

6. Hu JA, Li Y, Li S (2005) Verruciform xanthoma of the oral cavity: clinicopathological study relating to pathogenesis. APMIS 113: 629-634.

7. Mostafa KA, Takata T, Ogawa I, Ijuhin N, Nikai H (1993) Verruciform xanthoma of the oral mucosa: a clinicopathological study with immunohistochemical findings relating to pathogenesis. Virchows Arch A Pathol Anat Histopathol 423: 243-248.

8. Rawal SY, Kalmar JR, Tatakis DN (2007) Verruciform xanthoma: immunohistochemical characterization of xanthoma cell phenotypes. J Periodontol 78: 504-509.

9. Zegarelli DJ, Aegarelli-Schmidt EC, Zegarelli EV (1974) Verruciform xanthoma. A clinical, light microscopic, and electron microscopic study of two cases. Oral Surg Oral Med Oral Pathol 38: 725-734.

10. Cobb CM, Holt R, Denys FR (1976) Ultrastructural features of the verruciform xanthoma. J Oral Pathol 5: 42-51.

11. Kimura M, Ohto H, Shibata A, Enomoto A, Umemura M (2016) Clinicopathological and Immunohistochemical Characteristics of Verruciform Xanthoma of the Lower Gingiva: A Case Report. J Clin Diagn Res 10: ZD05-ZD06.

12. Qi Y, Sun Q, Yang P, Song A (2014) A case of multiple verruciform xanthoma in Gingiva. Br J Oral Maxillofac Surg 52: e1-e3.

13. Wu YH, Hsiao PF, Lin YC (2006) Verruciform xanthoma-like phenomenon in seborrheic keratosis. J Cutan Pathol 33: 373-377. 
Citation: Yamamoto H, Kawai M (2018) Histogenetic Study of Verruciform Xanthoma of the Gingiva. J Cytol Histol 9: 507. doi: 10.4172/2157-7099.1000507

Page 4 of 4

14. Matsuura H, Utsunomiya T, Campos EA (2003) A Histopathologica andlmmunohistochemical study of oral verruciform xanthoma. Nihon Univ J Oral Sci 29: 25-31.

15. Suka N (2007) Histogenetic study of verruciform xantoma. J Meikai Dent Med 36: 74-89.

16. Rowden D, Lovas G, Shafer W, Sheikh K (1986) Langerhans cells in verruciform xanthomas: an immunoperoxidase study of 10 oral cases. J Oral Pathol 15: 48-53.

17. Kantitakis J, Euvrard S, Butnaru AC, Claudy A (2004) Verruciform xanthoma of the scrotum in a renal transplant patient. Br J Dermatol 150: 161-163.

18. Polonowita AD, Firth NA, Rich AM (1999) Verruciform xanthoma and concomitant lichen planus of the oral mucosa. Int J Oral Maxillofac Surg 28: 62-66.

19. Furue M, Suzuki H, Kodama T, Hiramoto T, Sugiyama H, (1995) Colocalization of scavenger receptor in CD68 positive foam cells in verruciform xanthoma. J Dermatol Sci 10: 213-219.
20. Uchiyama N, Yamamoto A, Kameda K, Yamaguchi H, Ito M (2000) The activity of fatty acid synthase of epidermal keratinocytes is regulated in the lower stratum spinousum and the stratum basale by local inflammation rather than by circulating hormones. J Dermatol Sci 24: 134-141.

21. Proksch E1, Jensen JM, Elias PM (2003) Skin lipids and epidermal differentiation in atopic dermatitis. Clin Dermatol 21: 134-144.

22. Tabata T, Mine S, Kawahara C, Okada Y, Tanaka Y (2003) Monocyte chemoattractant protein-1 induces scavenger receptor expression and monocyte differentiation into foam cells. Biochem Biophys Res Commun 305: 380-385.

23. Robbesyn F, Salvayre R, Negre-Salvayre A (2004) Dual role of oxidized LDL on the NF-kappaB signaling pathway. Free Radic Res 38: 541-551. 